\title{
Gold-nanoparticles-graphene modified glassy carbon electrode for trace detection of lead ions
}

\author{
Yanchao Cheng ${ }^{1}$, Fangfang Sun ${ }^{1, *}$, Jaebeom Lee ${ }^{2}$, Tingchun Shi ${ }^{1}$, Tianze Wang ${ }^{1}$, and Yutong $\mathrm{Li}^{1}$ \\ ${ }^{1}$ College of Life Information Science and Instrument Engineering, Hangzhou Dianzi University, Hangzhou 310018, China \\ ${ }^{2}$ Department of Chemistry, Chungnam National University, Daejeon, Korea
}

\begin{abstract}
In order to fulfill rapid and trace detection of heavy metals, in the study, gold-nanoparticlesgraphene modified glass carbon electrodes were used to detect lead( $\mathrm{Pb}(\mathrm{II}))$ ions. The lead ion $(\mathrm{Pb}(\mathrm{II}))$ standard sample in acetic acid-sodium acetate buffer solution was detected by the modified electrode, and the detection conditions were optimized. Under the optimized conditions, in the buffer solution with $\mathrm{pH}=4.5$, the lead ions peak current showed excellent linear relationship with the lead ion concentration in the range of $0.2 \sim 50 \mu \mathrm{g} / \mathrm{L}\left(\mathrm{R}^{2}=0.995\right)$, and the minimum detection limit was $0.34 \mu \mathrm{g} / \mathrm{L}$. At the same time, the actual water samples were determined by nano-gold-graphene/glass carbon electrodes for lead ions, and the recovery ranges was $92.94 \% \sim 101.47 \%$, which showed that the gold-nanoparticles-graphene/glass carbon electrodes possessed significant detection performance for the actual water samples.
\end{abstract}

\section{Introduction}

Heavy metal pollution is one of the main problems of environment pollution, which seriously threatens the survival of aquatic organisms and human health[1,2]. Bioaccumulation of heavy metals like lead and its compounds enter the human body, which will cause a series of harms to nerves, digestion and kidneys, seriously affecting the health of the body[3, 4]. Lead ions $(\mathrm{Pb}(\mathrm{II}))$ are toxic to the human and animals and it has been found in various foods and water. There are a wide range of lead pollution in life, therefore, it is necessary to detect lead ions. With the development of analytical testing techniques, more and more methods are used to detect lead ions, such as Atomic Absorption Spectrometry(AAS), Atomic Fluorescence Spectrometry(AFS), Chemical Biological Method(CBM) etc[5-8]. However, these methods are complicated in operation and require pretreatment of samples. Anodic Stripping Voltammetry(ASV) has high sensitivity, good resolution, low cost and easy operation[9,10]. It can measure a variety of heaven metals at the same time. Therefore, it is suitable for rapid measurement of heavy metal ions. It was reported that modified glassy carbon electrode (GCE) such as noble metal nanomaterials[11], organic composite materials[12,13], and carbonyl nanomaterials $[14,15]$ have improved the adsorption capacity of electrodes for heavy metal ions, and the rapid trace determination of lead ions by square wave voltammetry(SWV). Göde et al.[16] used a functionalized calixarene-redox graphene modified glassy carbon electrode to improve the adsorption capacity of the electrode for heavy metal ions. Square wave voltammetry (SWV) was used to achieve lead ion.
Trace determination. Li et al.[11] used a nitrogen-doped carbon quantum dot-graphene oxide modified glassy carbon electrode to measure lead. The electrode has a wide linear range of $20 \sim 10 \quad 360 \mu \mathrm{g} / \mathrm{L}$ and a lower detection limit of $1.17 \mu \mathrm{g} / \mathrm{L}$. Nano-gold has the characteristics of high specific surface area and high electrical conductivity, which can vastly improve the adsorption capacity of glassy carbon electrodes for lead ions and improve the surface properties of GCE. In the study, nano-gold-graphene composite nanomaterials were used to modify the GCE to improve the performance of the electrode, and the rapid trace determination of lead ions in water samples was achieved.

\section{Materials and methods}

\subsection{Reagents and apparatus}

Graphene Oxide (GO) was purchased from XFNANO Co., Ltd(Nanjing, China). Gold chloride hydrate $\left(\mathrm{HAuCl}_{4}\right)$, lead nitrate $\left(\mathrm{Pb}\left(\mathrm{NO}_{3}\right)_{2}\right)$ were purchased from Aladdin (Shanghai, China). Acetic acid(HAc), sodium acetate $(\mathrm{NaAc})$, absolute ethanol was purchased from Sinopharm Chemical Reagent Co., Ltd (Shanghai, China). All reagents are analytically grade, and all solution were prepared by using ultrapure water with its resistance less than $18.2 \mathrm{M} \Omega \cdot \mathrm{cm}$.

The electrochemical experiments were carried out using CHI660E electrochemical workstation $(\mathrm{CH}$ Instruments, Chenhua Co., Shanghai, China) at constant temperature with a three-electrode system. The working electrode was a AuNPs-GR/GCE, and the GCE was

\footnotetext{
* Corresponding author: sunff511@hdu.edu,cn
} 
purchaed from aida Insrtuments (Tianjin, China). A saturated calomel electrode (CHI150) was used as the reference electrode and a platinum wire (CHI115) was used as the counter electrode, both provided by $\mathrm{CH}$ Instruments (Shanghai, China).

\subsection{Preparation of electrodes}

The glassy carbon electrode $(\Phi=3 \mathrm{~mm})$ was smoothed on the suede polishing cloth with $1,0.3,0.05 \mu \mathrm{m} \mathrm{Al}_{2} \mathrm{O}_{3}$, and sequentially ultrasonic cleaning for $2 \mathrm{~min}$ in $1: 1$ nitric acid solution, 1:1 ethanol solution, and ultrapure water, respectively. Finally, dry with nitrogen. First, 1 $\mathrm{mg} / \mathrm{mL}$ of $\mathrm{GO}$ was diluted to $0.3 \mathrm{mg} / \mathrm{mL}$, and then 0.5 $\mu \mathrm{L} 0.3 \mathrm{mg} / \mathrm{mL} \mathrm{GO}$ was dropped onto the surface of the GCE and dried under infrared lamp with room temperature. The second, AuNPs-GR/GCE nanomaterial modified electrode was prepared by cyclically scanning the dried $\mathrm{GO} / \mathrm{GCE}$ electrode in a $0.5 \mathrm{~mol} / \mathrm{L} \mathrm{NaCl}$ solution from $-1.3 \mathrm{~V}$ to $0.8 \mathrm{~V}$ for 10 cycles.

\subsection{Preparation of water samples}

Water samples were used to evaluate whether the performance of the prepared electrodes could be used for the detection of actual samples. The water sample is filtered through standard $0.45 \mu \mathrm{m}$ filter paper. Prior to testing, the $\mathrm{pH}$ of the sample was adjusted to 4 with 0.1 $\mathrm{mol} / \mathrm{L}_{\mathrm{HNO}}$.

\subsection{Methods of experiment}

$0.1 \mathrm{~mol} / \mathrm{L}$ acetic acid-sodium acetate buffer solution and lead standard solution was put in a $10 \mathrm{~mL}$ electrolytic cell. The modified AuNPs-GR/GCE electrode was the working electrode, the platinum wire was the counter electrode, and the saturated calomel electrode was the reference electrode. Enriched for a certain time at a voltage of $-1.2 \mathrm{~V}$ with stirring at $100 \mathrm{r} / \mathrm{min}$. After standing for $10 \mathrm{~s}$, the scanning results of square wave voltammetry were recorded. The parameters of the square wave voltammetry were as follows, scan interval: $-1.2 \sim 0.2 \mathrm{~V}$; potential increase: $5 \mathrm{mV}$; square wave frequency: $25 \mathrm{~Hz}$; square wave amplitude: $25 \mathrm{mV}$; pulse amplitude: $0.025 \mathrm{~V}$; pulse width: 0.25 ; pulse period: 0.4 s.

\section{Result and discussion}

\subsection{The performance of AuNPs-GR/GCE electrodes}

Electrochemical impedance spectroscopy (EIS) was carried out using a potentiostat/galvanostat (CHI660E) with frequency response analyzer (FRA). The scanning frequency ranged from $5 \cdot 10^{4}$ to $1.5 \mathrm{~Hz}$ and amplitude $0.01 \mathrm{~V}$. Fib. 1 showed the result of EIS for bare GCE, GR/GCE and AuNPs-GR/GCE electrodes for equimolar concentration $0.02 \mathrm{M}\left[\mathrm{Fe}(\mathrm{CN})_{6}\right]^{3-/ 4-}$ in $0.1 \mathrm{M} \mathrm{KCl}$. The Faradaic impedance spectra presented as Nyquist plots.
The electron transfer resistance of GCE, GR/GEC, AuNPs-GR/GCE is close to $180 \Omega \mathrm{cm}^{-2}, 46 \Omega \mathrm{cm}^{-2}$ and $30 \Omega \mathrm{cm}^{-2}$, respectivly (Fig.1). The result showed that nano-gold further reduced the electron transfer resistance and improved the electron transfer efficiency. It could be attributed to the fact that the AuNPs increased the specific surface area of the electrode and facilitate electron transfer.

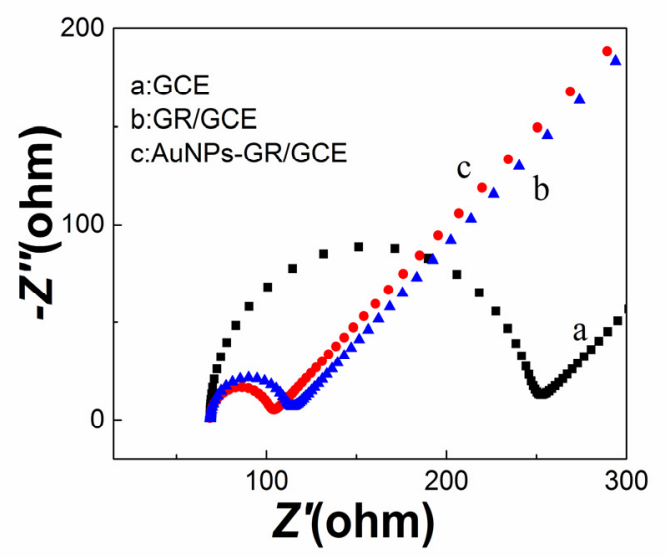

Fig.1. The resistance of GCE(a), GR/GCE(b) and AuNPsGR/GCE(c).

\subsection{Parameters optimization for the fabrication of the AuNPs-GR/GCE electrodes}

As we know, the electrode surface materials play a crucial role in the performance of the electrode, therefore, experimental design was used to optimize the most influential parameters in the fabrication of the AuNPsGR/GCE electrode: the concentration of GO, the numbers of circle and deposition time of the preparation of AuNPs. The layer thickness of graphene is an important factor affecting the performance of the electrode. Therefore, the concentration of graphene oxide is set as $0.05 \mathrm{mg} / \mathrm{mL}, 0.1 \mathrm{mg} / \mathrm{mL}, 0.2 \mathrm{mg} / \mathrm{mL}, 0.3$ $\mathrm{mg} / \mathrm{mL}, 0.5 \mathrm{mg} / \mathrm{mL}, 0.7 \mathrm{mg} / \mathrm{mL}$, the electrode measures the peak current of the concentration of lead ions was 40 $\mu \mathrm{g} / \mathrm{L}$. Fig. 2a shows that the optimum measurement results shows that the concentration of graphene oxide is $0.3 \mathrm{mg} / \mathrm{mL}$. Therefore, the optimum concentration of graphene oxide was selected as $0.3 \mathrm{mg} / \mathrm{mL}$. Fig. $2 \mathrm{~b}$ and c shows the peak current with different cycling numbers and deposition rate of the deposition AuNPs. The result showed that the peak current was maximum when the circling numbers was 10 and $10 \mathrm{Mv} / \mathrm{s}$. It can be seen from the results that the deposition parameters of gold nanoparticles have a significant influence on the performance of the electrode. When the cycling numbers and scanning rate are excessive, the morphology of AuNPs on the surface of the electrodes are inhomogeneity, which will decrease the specific surface area thus decrease the absorption capacity of lead ions. 


\subsection{Optimization of parameters for the detection of lead $(\mathrm{Pb}(\mathrm{II}))$}

The existence form of heavy metal ions is heavily affected by $\mathrm{pH}$, thus $\mathrm{pH}$ is an important factor affecting the detection of heavy metal ions. Fig. 3a shows the effect of the $\mathrm{pH}$ on the detection of $40 \mu \mathrm{g} / \mathrm{L} \mathrm{Pb}(\mathrm{II})$ in acetic acid-sodim acetate buffer solution. When the $\mathrm{pH}$ rises from 2 to 4.5 , the peak current gradually increases However, the peak current will dramatic decrease when the $\mathrm{pH}$ is higher than 4.5. Lead ions exist in the form of their compounds under alkaline conditions, in general, $\mathrm{pH}=4.5$ is the optimum detecting condition. Fig. $3 \mathrm{~b}$ and $\mathrm{c}$ show the effect of deposition potential and deposition time on the detection of $40 \mu \mathrm{g} / \mathrm{L}$ lead ion solution. The deposition time was set as a constant. When the deposition potential changeed from $-0.8 \mathrm{~V}$ to $-1.4 \mathrm{~V}$, the peak current increased gradually. However, when the deposition potential was $-1.2 \mathrm{~V}$ or more negative, the phenomenon of "hydrogen evolution" on the electrode surface was serious. Affect the stability of the electrode on lead ion detection, therefore, $-1.2 \mathrm{~V}$ was chosen as the optimal deposition potential (Fig.3b). Fig.3c shows that as the deposition time changed from 30 s to $180 \mathrm{~s}$, the peak current gradually increaseed. After 180 s, the peak current tended to be stable, so 180 s was selected as the optimal deposition time.
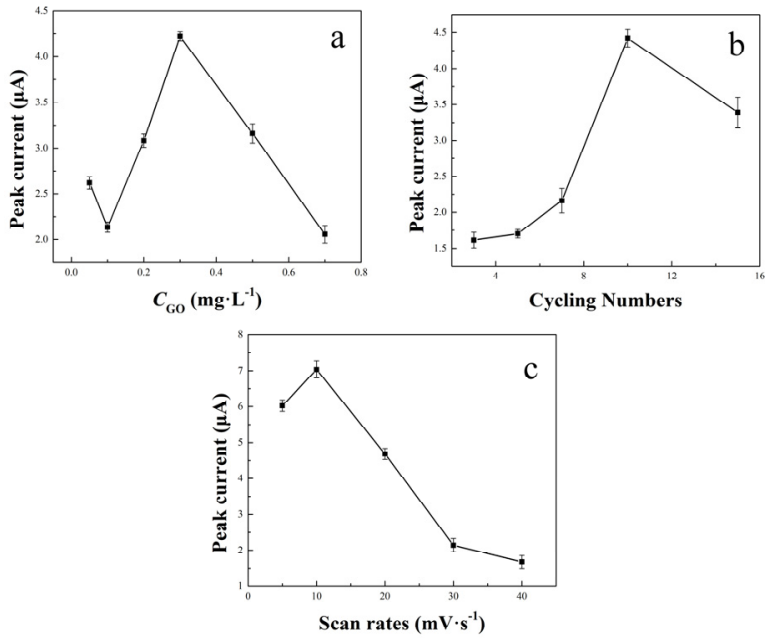

Fig.2. The optimization of modified electrode paramters. a: concentration of RO, b: cycling numbers, c: scan rate

\subsection{The determination of $\mathrm{Pb}$ ( II )}

Under the above optimal conditions, the standard lead solution was subjected to anodic stripping voltammetry using AuNPs/GR modified glsaa catbon electrode. The results of the lead standard samples are shown in Fig. $4 \mathrm{a}$. In the interval of $0.2 \sim 50 \mu \mathrm{g} / \mathrm{L}$, the electrode has good linearity for $\mathrm{Pb}(\mathrm{II})$ detection. As the lead concentration increases, the current signal of anodic stripping voltammetry also increases, and the electrode shows great performance. The theoretical lower limit of detection is $0.37 \mu \mathrm{g} / \mathrm{L}$ (Fig. 4a). Under the condition of 180 s of deposition time, the linear regression equation of the electrode in the range of $0.2-50 \mu \mathrm{g} / \mathrm{L}$ is $\mathrm{I} p(\mu \mathrm{A})=$ $0.2408 \mathrm{C}+0.4323\left(\mathrm{R}^{2}=0.992\right)$.

\subsection{Repeatability, reproducibility, and anti- interference of AuNPs-GR/GCE}

At the same time, the stability, repeatability and antiinterference ability of nano-gold/graphene modified glassy carbon electrode were studied. The experimental results are shown in Fig. 5. The obtained RSDs values of $3.4 \%$ for $\mathrm{Pb}(\mathrm{II})$ showed that the stripping signals of $40 \mu \mathrm{g} / \mathrm{L} \mathrm{Pb}(\mathrm{II})$ were highly reproducible (Fig.5a). The peak currents of $40 \mu \mathrm{g} / \mathrm{L} \mathrm{Pb}(\mathrm{II})$ at one AuNPs-GR/GCE after six measurements are compared to evaluate the repeatability of the electrode. The relative standard deviation (RSD) is $0.8025 \%$ (Fig. 5 b), the result showed the AuNPs-GR/GCE electrode possessed excellent stability. The effects of $\mathrm{K}^{+}, \mathrm{Cl}^{-}, \mathrm{Na}^{+}, \mathrm{Mg}^{2+}, \mathrm{SO}_{4}{ }^{2-}, \mathrm{Ca}^{2+}$, $\mathrm{NO}_{3}{ }^{-}$on the detection were studied. The results showed that the above ions have less than $5 \%$ effect on the peak current at equivalent concentration(Fig.5c).

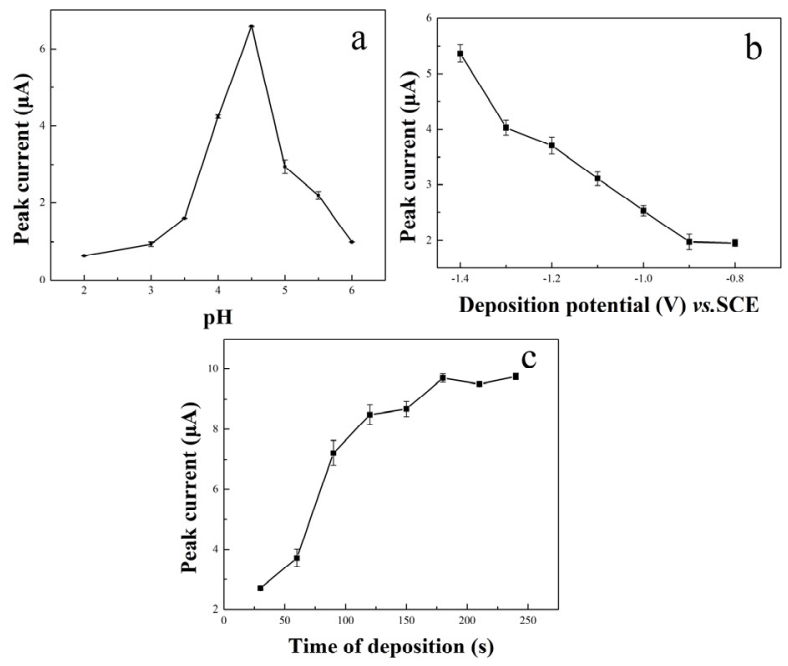

Fig.3. The optimization of detection conditions. a: $\mathrm{pH}, \mathrm{b}$ : deposition potential, c: deposition time
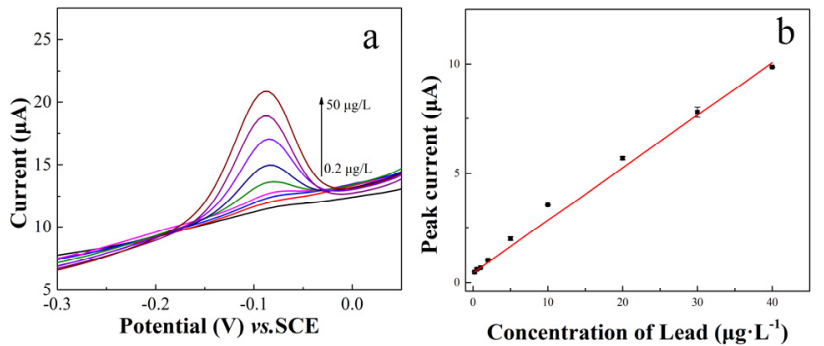

Fig.4. Square wave anodic stripping voltammograms for $\mathrm{Pb}($ II $)$.

\subsection{Real water sample analysis}

In order to evaluate the performance of AuNPs-GR/GCE electrodes, the detection of $\mathrm{Pb}$ ( II ) in the water was studied as provided in 2.3. The result showed at table 1 . There was no detectable $\mathrm{Pb}$ (II) in the sample of water. 
After addition of $\mathrm{Pb}$ ( II ) standard solutions at different concentrations, satisfying recoveries of 92.94\% 101.47\%. In general, $\mathrm{Pb}$ ( II ) can be detected quickly and efficiently by the AuNPs-GR/GCE electrodes.

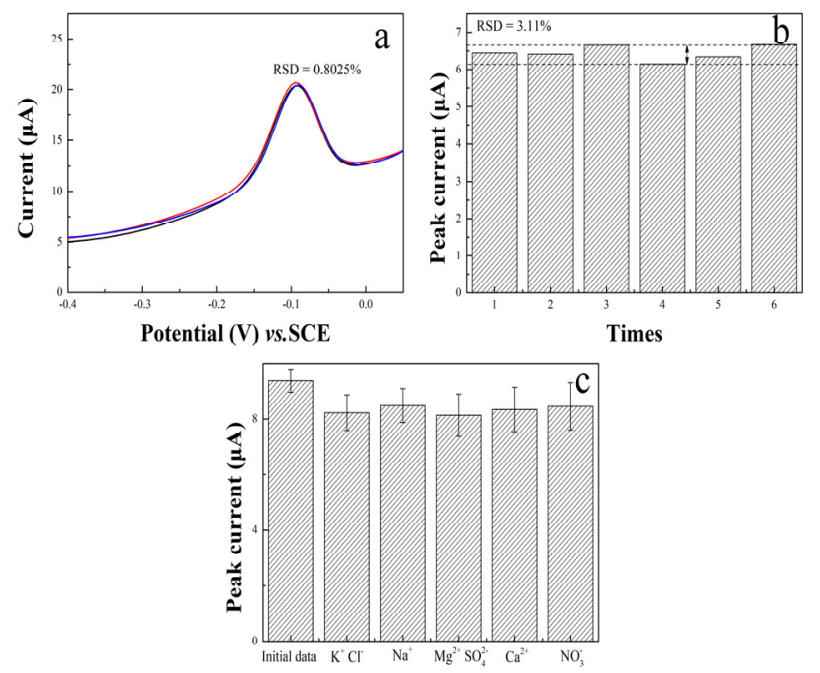

Fig.5. The Repeatability, reproducibility, stability and antiinterference of AuNPs-GR/GCE.

Table 1 Determination of $\mathrm{Pb}$ ( II ) in water using AuNPsGR/GCE electrode.

\begin{tabular}{llccc}
\hline $\begin{array}{l}\text { Sampl } \\
\mathrm{e}\end{array}$ & $\begin{array}{l}\text { No } \\
\cdot\end{array}$ & $\begin{array}{c}\text { Added } \\
\text { content } \\
(\mu \mathrm{g} / \mathrm{L})\end{array}$ & $\begin{array}{c}\text { Measurd } \\
\text { value }(\mu \mathrm{g} / \mathrm{L})\end{array}$ & $\begin{array}{c}\text { Recover } \\
\mathrm{y} \text { rate/\% }\end{array}$ \\
\hline & 1 & 0 & 0 & 0 \\
& 2 & 20 & 19.19 & 95.94 \\
& 3 & 30 & 30.44 & 101.47 \\
Water & 4 & 35 & 32.53 & 92.94 \\
& 5 & 40 & 38.76 & 96.90 \\
& 5 & 45 & 45.03 & 100.07 \\
\hline
\end{tabular}

\section{Conclusion}

In summary, in this study, nano-gold-graphene modified glassy carbon electrodes were used to detect lead ions in water. The electrochemical properties of the electrode were characterized by cyclic voltammetry. The experimental results showed that the performance of the glassy carbon electrode was considerably improved after the modification of nano-gold-graphene composite. The electrode performance has been greatly improved after modification with AuNPs and graphene composites on the surface of glassy carbon electrode, which due to the nanomaterials increased the specific suface area and the adsorpation capacity to lead ions $(\mathrm{Pb}(\mathrm{II}))$. The detection conditions of $\mathrm{Pb}(\mathrm{II})$ in the electrode were studied and optimized. The detection conditions of the lead ion standard sample were optimized, and under the optimized conditions, the linear range of the
AuNPs/GR/GCE electrode to lead ions( $\mathrm{Pb}$ ( II )) was $0.2 \sim 50 \mu \mathrm{g} / \mathrm{L}\left(\mathrm{R}^{2}=0.985\right)$. The minimum detection limit was $0.37 \mu \mathrm{g} / \mathrm{L}$. The sample of water was measured by standard addition method, the recovery rate was 92.94\% 101.47\%. Therefore, the AuNPs/GR/GCE electrodes have a great potential to be applied in actual detection fo $\mathrm{Pb}(\mathrm{II})$.

\section{Acknowledgments}

This study was supported by the Public Welfare Project of Zhejiang Province of China (2016C33077), KoreaChina Young Scientist Exchange Program(2017).

\section{References:}

1. L. Xiao, B. Wang, L. Ji, F. Wang, Q. Yuan, G. Hu, A. Dong, and W. Gan, Electrochimica Acta 222, 1371 (2016).

2. S. Naghdi, K. Y. Rhee, D. Hui, and S. J. Park, COATINGS 8 (2018).

3. S. Alim, J. Vejayan, M. M. Yusoff, and A. K. M. Kafi, BIOSENSORS \& BIOELECTRONICS 121, 125 (2018).

4. W. Jin and G. Maduraiveeran, JOURNAL OF ANALYTICAL SCIENCE AND TECHNOLOGY 9 (2018).

5. I. M. Isa, M. I. Saidin, M. Ahmad, N. Hashim, S. A. Bakar, N. M. Ali, and S. M. Si, Electrochimica Acta 253, 463 (2017).

6. H. Xu, S. Xing, L. Zeng, Y. Xian, G. Shi, and L. Jin, Journal of Electroanalytical Chemistry 625, 53 (2009).

7. E. Paramo, S. Palmero, A. Heras, and A. Colina, Talanta 178, 736 (2018).

8. F. Cai, Q. Wang, X. Chen, W. Qiu, F. Zhan, F. Gao, and Q. Wang, Biosensors and Bioelectronics 98, 310 (2017).

9. F. A. Gutierrez, J. M. Gonzalez-Dominguez, A. Ansón-Casaos, J. Hernández-Ferrer, M. D. Rubianes, M. T. Martínez, and G. Rivas, Sensors and Actuators B: Chemical 249, 506 (2017).

10. S. Li, C. Zhang, S. Wang, Q. Liu, H. Feng, X. Ma, and J. Guo, ANALYST 143, 4230 (2018).

11. L. Li, D. Liu, A. Shi, and T. You, Sensors and Actuators B: Chemical 255, 1762 (2018).

12. C. Dong, J. Lu, B. Qiu, B. Shen, M. Xing, and J. Zhang, Applied Catalysis B: Environmental 222, 146 (2018).

13. Z. Lu, J. Zhang, W. Dai, X. Lin, J. Ye, and J. Ye, Microchimica Acta 184, 4731 (2017).

14. M. Sebastian and B. Mathew, Journal of Materials Science 53, 3557 (2018).

15. M. Sýs, R. Metelka, L. Korecká, H. Pokorná, and I. Švancara, Monatshefte für Chemie - Chemical Monthly 148, 505 (2017). 
16. C. Göde, M. L. Yola, A. Yılmaz, N. Atar, and S. Wang, Journal of Colloid and Interface Science 508, 525 (2017). 